\title{
Country of origin and willingness to pay for pistachios: a chinese case
}

\author{
Pei $\mathrm{Xu}^{1 *}$ and Zhigang Wang ${ }^{2}$
}

\author{
* Correspondence: \\ pxu@csufresno.edu \\ ${ }^{1}$ California State University at Fresno, \\ Department of Agricultural Business, \\ 5245 N Backer Avenue, M/S PB101, \\ Fresno, CA 93740-8001, USA \\ Full list of author information is \\ available at the end of the article
}

\begin{abstract}
Using 360 questionnaire data collected in Beijing, China, this study examines consumers' acceptance and willingness to pay (WTP) for pistachios produced in China, California and Turkey. The impact of country of origin (COO), price, flavor, package size and package type was analyzed. A conditional logit model shows that consumers are willing to pay a statistically significant premium for California and Chinese pistachio, but the Turkish pistachio is less preferred. Using a mixed logit model to estimate the income effect, this study shows that wealthier consumers tend to purchase California pistachio. The marginal effect shows that every $1 \%$ increase in income will result in a 1.2\% increase in the probability of purchasing California pistachio. However, the purchase of Chinese pistachio does not depend on income.

Price and $\mathrm{COO}$ are the two most influential attributes and package size and type are the two least important attributes to change derived utility.
\end{abstract}

Keywords: Pistachios; Price acceptance; Willingness to pay; Country of origin impact; Conjoint analysis; Pistachio consumption demand in China

\section{Background}

Food consumption patterns in China have evolved in the past decade due to expanded consumer disposable income, new desires for Western lifestyle, and heightened food safety concerns (Wang et al. 2008; Xu et al. 2010; Ortega et al., 2011; Xu et al. 2012). With a greater income to spend, the demand for healthful foods with added nutrition features has gone up progressively (Fuller et al. 2006; Wang et al. 2008). The demand for pistachios as a healthful snack food has arisen: as the world's sixth largest grower, China consumes most of its domestically produced pistachios. However, the market share for domestically grown nuts is declining to lower than $50 \%$ in 2014, primarily due to food safety concerns (China Commerce, 2013). It was publicized in 2013 that Chinese suppliers used sulphur, a toxic chemical, to color pistachios to make the nuts look appealing. California and Turkey are China's primary international suppliers who ship a total of 12 million pounds of pistachios to China each year (Tech-food.com 2006; PistachioHealth.com, 2012; Askci.com, 2012). China is the outmost export market for these two countries: California sells 17\% (\$109 million value; a market share of 13\%, Enorth, 2008) (South China Morning Post, 2013; Weston, 2013) and Turkey ships $18 \%$ of its total crops to China (USDA, 2003). However, anecdotal evidences revealed that California pistachios are unsafe due to salmonella contaminations (Sohu, 2009). To develop efficient marketing strategies and rebuild consumption confidence, international marketers and stakeholders, including those from California,

(c) 2014 Xu and Wang; licensee Springer. This is an Open Access article distributed under the terms of the Creative Commons Attribution License (http://creativecommons.org/licenses/by/4.0), which permits unrestricted use, distribution, and reproduction in any medium, provided the original work is properly credited. 
have sought academic help to better understand Chinese consumers' pistachio purchase preference. To compete with foreign suppliers, Chinese domestic pistachio marketers have also looked for academic help to learn factors affecting pistachio purchase choices.

A paucity of published information shows that pistachios have become many city duelers' most favored snack food for which they are willing to spend \$10-20 per month, and the quantity demanded is rising (China Food News, 2012). In contrast, a decade ago, pistachios were often presented during major Chinese holidays, or used as a luxury gift to please relatives and close friends for the wish of happiness and good fortune. With Pistachio's health attributes being better understood, it wins the Chinese name: the happy nuts. The growing demand may implicate the need for new market interventions to ensure the supply of safe and desirable pistachios. However, little, if any academic research has dedicated to understand the preferred pistachio features. This study is the first to quantify the impact of price, country-of-origin (COO), product flavor, package-size and package type on pistachio choices.

Different from necessity staples, pistachios are an expensive luxury snack food that offers enjoyment and comfort, and the demand can greatly change with income. Before 1995, when consumer disposable income was small, the demand was found low. Lately, China's rapid economic growth and its strengthened integration to the global economy have propelled a greater need for this luxury snack food. However, none of published work can explain factors driving the demand change and the magnitude of the change. Published food demand analyses in China have exclusively emphasized the demand for necessity staples, such as rice, pork, fish, and milk (Zhang et al. 2010; Ortega et al. 2011; De Steur et al. 2012; Zheng et al. 2012; Xu et al. 2012). These analyses show that Chinese consumers tend to use price as a quality cue and they appear to prefer a higher priced item, assuming it has a better quality. Is price a concern when consume pistachios? A preliminary market research we conducted shows that imported pistachios are priced at 60 Yuan to 180 Yuan per 500 grams (\$9.5-28.6, $1 \$=6.3$ Yuan). The preliminary research did not show that California pistachios are priced higher than domestic produced or imported products from other countries. The package size varies from small size of about 125 grams to large size of about 500 grams. This study analyzes the impact of price on pistachio choice. Findings may shed light to new consumption trend about healthful snack food in general.

This study also differs from published work to take into account the impact of $\mathrm{COO}$ on pistachio choice. The literature highlights the impact of consumption experience, retail formats, brands, and government certifications on Chinese consumers' food decisions (Wang et al. 2008; Zhang et al. 2010; Ortega et al. 2011; Xu et al. 2012). Given the substantial presence of imported pistachios from Turkey and from California, including $\mathrm{COO}$ as an explanatory variable is necessary. This study analyzes consumer rankings about thirty-six different pistachio profiles to understand: 1) how price and $\mathrm{COO}$ affect buying decisions; 2) whether original non-flavored pistachios is preferred to the flavored alternative; 3) how non-gift packed products is liked compared to the gift-packed alternative; and 4) how consumers' income level affects their price, $\mathrm{COO}$, flavor and package preference.

\section{Methods}

A summary of selected attributes appears in Table 1. Marketing researchers view COO as a salient cue that affects buyer perceptions of quality (White and Cundiff, 1978). It 
Table 1 Selected attributes

\begin{tabular}{ll}
\hline Attributes & Levels \\
\hline Country of origin & China \\
& California \\
Price & Turkey \\
& Opt-out \\
& 80 Yuan $/ 500$ grams \\
Flavor & 100 Yuan $/ 500$ grams \\
& 120 Yuan $/ 500$ grams \\
Package size & Original flavor (no salt no sweet) \\
& Sweet flavor \\
Gift pack & Salt flavor \\
& 125 grams \\
\hline
\end{tabular}

also affects product evaluation process and it changes belief formation about a product that has a significant import presence (Erickson et al. 1984). COO was also found to be a deterministic factor affecting food choices and the literature emphasizes beef choices. Schnettler et al. (2004) (cited in Schnettler et al. 2008) showed that imported products were perceived to have lower quality than local beef. Loureiro and Umberger (2007) interviewed 5000 U.S. consumers to examine factors affecting the demand of beef ribeye steaks. They discovered that COO is less important than a USDA food safety label on beef choices. The $\mathrm{COO}$ attribute is critical to pistachio choices and this study addresses the impact of significant presence of imported pistachios.

It is important to help marketers understand whether Chinese consumers prefer sweetened or salted pistachio and how much price premium they are willing to pay to get the preferred taste. Daillant-Spinnler et al. (1996) examined how flavor changes consumption choices of apples and concluded that some consumers preferred sweet and hard apples and some preferred acidic and juicy apples. Blackman et al. (2010) examined taste preference for wine products and found that experienced consumers preferred wine with less sweetness and new consumers favored wine with more sweetness. Though information is limited to understand Chinese consumers' preference for sweetness, information about Asian consumers sweetness preference is available. Comparing the sweetness and saltiness likings of Japanese and Australia consumers, Laing et al. (1994) showed that Japanese consumers agreed with Australia consumers about the sweetness strength of biscuits, jams, chocolates, breakfast cereals, and fruit juice, but they showed great difference in sweetness likings. They rated higher sweetness liking to products produced in their own country. Prescott et al. (1993) studied Japanese and Australia consumers' preference for salty crackers and found that Japanese rated the saltiness intensity similarly as Australia consumers. However, to Japanese, the overall product feature rather than the saltiness content affected the likings rating. Taste may greatly affect pistachio choice and this study asks respondents to rate their preference for saltiness and sweetness to find out how Chinese consumers like the flavored pistachios. 
Despite the fact that package greatly influences snack food selection, research related to snack food package preference is scant. Mayen et al. (2007) studied the impact of packaging on Indiana consumers' choice of fresh-cut melon products and found that consumers are willing to pay a price premium for a squared packed product than a cup packed one. The impact of package size and gift- or non-gift package is analyzed in this study to evaluate how packaging affects pistachio willingness to pay.

A choice-based conjoint (CBC) analysis is used to elicit consumers' WTP for pistachios.

This study asked each respondent to rank four alternative products: the first three alternatives feature a different country where the product is from, and the last alternative refers to "I do not like any of the product". The small choice set helps reduce respondents' cognitive burden. Tcornhese four alternatives are randomly selected from a computer generated full factorial design. According to Lusk and Norwood (2005), the random selection maintains orthogonality of the picked attributes; it performs well when the impact is analyzed using discrete utility functions; and it enables the estimation of the impact from interacted attributes. Each respondent completed three choice cards. A sample choice card shows in Table 2. Respondents also completed 32 other questions about consumption frequency and quantity, retail outlets visited, factors affecting choices, and demographics.

Graduate agricultural economics students from a Chinese university administered preliminary face-to-face interviews with Beijing consumers in late December 2011 to find out which factors affect pistachio purchase. These interviews helped select COO, price, sweet or salty, gift package or regular package, and package size as the attributes. Graduate students from the same Chinese university administered the face-to-face interviews in Beijing's seven districts in mid January 2012: Haidian (21\%), Chaoyang (23\%), Mentougou (4\%), Shijingshan (4\%), Xicheng (16\%), Fengtai (17\%), and Dongcheng (15\%). Randomly selected respondents completed the survey in large supermarkets (70\%), such as Wal-Mart, Chaoshifa Superstores, and Carrefour stores; in small- or mid- size supermarkets (21\%), such as Chengnanjiayuan and Quchenshi stores; and in subway stations and randomly selected fruits and nuts stands (9\%). More than $90 \%$ of the interviews were conducted at the dry nuts section in selected stores. Interviews took place a week before China's Spring Festival when many consumers shop for dry nuts as a holiday gift. Gathering data during this holiday season allowed us to recruit more respondents and we were also able to include in our sample respondents shopping for their own and those shopping for a gift. A total of 360 completed questionnaires were analyzed.

Table 2 A sample choice card

\begin{tabular}{llllll}
\hline $\begin{array}{l}\text { Please circle } \\
\text { One product }\end{array}$ & Country of origin & Price (Yuan/500 grams) & Flavor & $\begin{array}{l}\text { Package weight } \\
\text { (in gram) }\end{array}$ & Package type \\
\hline 1 & China & 120 & Salt & 500 & Gift pack \\
2 & California, U.S. & 80 & Salt & 125 & Regular pack \\
3 & Turkey & 120 & Sweet & 250 & Gift pack \\
4 & I do not like any & & & & \\
\hline
\end{tabular}


According to Lancaster's random utility theory (Lancaster 1966), the utility of the $i^{\text {th }}$ consumer $\mathrm{U}_{i}(i=1, \ldots, I)$ derived from the $j^{\text {th }}$ product alternative (out of a choice set of $C$ ) is a function of the selected attributes of alternative $j$ :

$$
U_{i j}=\beta x_{i j}+\varepsilon_{i j}
$$

Where $\beta$ is a vector of unknown parameters of interest, $x$ is a vector of attributes for product $j$ selected by consumer $i$, and $\varepsilon$ is a stochastic error term resulted from measurements errors.

According to McFadden (1974), the probability $P_{i j}$ that an individual $i$ will choose alternative $j$ from choice set $C$ equals the probability that the utility associated with choice $j$ is greater than the utility associated with all other $k$ choices in the same choice set. Thus,

$$
\begin{aligned}
& P_{i j}=P\left(\beta x_{i j}+\varepsilon_{i j}>\beta x_{i k}+\varepsilon_{i k}\right) \\
& P_{i j}=P\left(\varepsilon_{i j}-\varepsilon_{i k}>\beta x_{i j}-\beta x_{i k}\right), j \neq k
\end{aligned}
$$

Assume the error terms are independent and identically distributed with the Weibull (Gnedenko, extreme value) distribution (McFadden 1974), $P_{i j}$ is:

$$
P_{i j}=\frac{\exp \left(\beta x_{i j}\right)}{\sum_{k=1}^{j} \exp \left(\beta x_{i k}\right)}
$$

In the above conditional logit model, $x$ represents product attributes only. The model assumes the characteristics of respondents are the same across the sample.

In order to control heterogeneity of respondents' individual specific characteristics, a mixed logit model is applied. This model allows the interaction between individual specific characteristics and product attributes in the estimation (Train, 2003; Colombo et al. 2007). For individual $i$, the random parameters $\beta$ can be specified as:

$$
\beta \sim H(\theta, v)
$$

where $\mathrm{H}($.$) is a probability distribution function with mean \theta$ and variance $v$ of the underlying distribution function. The probability of individual $i$ choose alternative $j$ is given by:

$$
P_{i j}=\int \frac{\exp \left(x_{i j} \beta\right)}{\sum_{k=1}^{j} \exp \left(x_{i k} \beta\right)} \delta(\beta) d \beta
$$

where $\delta(\beta)$ is the joint density function for the random parameter $\beta$ (Hu et al. 2009; Chang et al. 2012). Willingness to pay (WTP) estimates the amount of money an individual consumer is willing to give up to exchange for benefits of a specific product attribute. According to Lusk and Norwood (2005), Mayen et al. (2007) and Chang et al. (2012), WTP can be computed using:

$$
W T P_{j}=\frac{\beta_{j=1}-\beta_{j=0}}{-\beta_{\text {price }}}
$$

The variance of WTP is estimated using (Greene, 2000): 


$$
\operatorname{var}[W T P] \approx\left(\frac{\partial W T P}{\partial \beta}\right)^{\prime}(\operatorname{var}[\hat{\beta}])\left(\frac{\partial W T P}{\partial \beta}\right)
$$

The gathered data were analyzed using the following model (McFadden, 1974).

$$
\begin{aligned}
\text { Utility }= & \beta_{1}(\text { California })+\beta_{2}(\text { China })+\beta_{3}(\text { Turkey }) \\
& +\beta_{4}(\text { Price })+\beta_{5}(\text { salt })+\beta_{6}(\text { sweet }) \\
& +\beta_{7}(\text { gift })+\beta_{8}(\text { midsize })+\beta_{9}(\text { largesize })
\end{aligned}
$$

The first three coefficients in equation (8) estimate the impact of $\mathrm{COO}$ on derived utility. These three coefficients are relative to the coefficient of the opt-out alternative. The impact of the salt and sweet attributes was relative to the original favor alternative, which was the base and was omitted in the estimation. The gift attribute's impact was estimated relative to the non-gift package alternative, which was omitted, too. The medium size (250 grams) and large size (500 grams) attributes' impact was relative to the small size (125 grams) alternative, which was omitted as well. Respondents were expected to select the lower priced alternative rather than the higher priced one, resulting in a negative price coefficient. STATA 11 econometric software was used to estimate the parameters.

\section{Results and discussion}

Respondents' demographics appear in Table 3. The sample includes people from different age, gender, education and income groups. A majority of these respondents are 40 years or younger $(72 \%)$ and more females answered the survey (55\%). Given the fact that interviews were mostly conducted at the dry nuts section, it seems to suggest that younger females are more likely to visit this section. The sample's mean monthly income is 6000 Chinese Yuan ( $\$ 952 ; 1$ USD $=6.3$ Chinese Yuan) with 55\% respondents reported an income of more than 6000 Yuan. The sample's average household size is 3.25 with $65 \%$ respondents reported a household size of three or fewer. This household size statistics is higher than the published national average household size statistics of 2.45 (The Six National Population Census, Beijing, 2014). The sample's per capita income of 1846 Yuan (\$293) is a little lower than the published Beijing per capita income, which was \$317 in 2011 (Beijing Statistical Information Net, 2011). The sample's education level is higher than the 2011 published Beijing average education level which shows that $20.56 \%$ of the Beijing population have a bachelor's degree (Chen et al. 2006). Our sample shows that $34 \%$ of the respondents have a bachelor's degree. $70 \%$ of the respondents reported they do not have a family member younger than 14 and $55 \%$ of them reported that they do not have a family member older than 50. Thus, many of the respondents do not have a dependent child and they also do not have elderlies to support.

Table 4 shows the reported pistachio purchase behavior. Fifty four percent of the respondents would purchase 500 grams or more each time they visit a store. Among them, 25\% would purchase 1500 grams or more. This high purchase quantity comes with a high purchase frequency: $31 \%$ of them make a purchase once every month or more often. Though the sample seems to suggest a high consumption demand, it also reveals that $38 \%$ of the respondents make a purchase only when the family celebrates major holidays; and $19 \%$ of them do not buy pistachios. However, $31 \%$ of the 
Table 3 Respondents' demographics

\begin{tabular}{|c|c|c|}
\hline$(n=360)$ & Frequency & Percentage \\
\hline \multicolumn{3}{|l|}{ Age } \\
\hline $18-25$ & 108 & $30 \%$ \\
\hline $26-40$ & 152 & $42 \%$ \\
\hline $41-55$ & 57 & $16 \%$ \\
\hline Above 55 & 26 & $7 \%$ \\
\hline No response & 17 & $5 \%$ \\
\hline Total & 360 & $100 \%$ \\
\hline \multicolumn{3}{|l|}{ Gender } \\
\hline Male & 159 & $44 \%$ \\
\hline Female & 198 & $55 \%$ \\
\hline No response & 3 & $1 \%$ \\
\hline Total & 360 & $100 \%$ \\
\hline \multicolumn{3}{|c|}{ Household Monthly Income (Chinese Yuan) } \\
\hline 2500 or less & 35 & $10 \%$ \\
\hline $2501-6000$ & 128 & $35 \%$ \\
\hline $6001-9000$ & 67 & $19 \%$ \\
\hline Above 9000 & 130 & $36 \%$ \\
\hline Total & 360 & $100 \%$ \\
\hline \multicolumn{3}{|l|}{ Household member } \\
\hline Two or fewer & 75 & $21 \%$ \\
\hline Three & 159 & $44 \%$ \\
\hline Four & 84 & $23 \%$ \\
\hline Above four & 42 & $12 \%$ \\
\hline Total & 360 & $100 \%$ \\
\hline \multicolumn{3}{|l|}{ Education } \\
\hline High school or below & 82 & $23 \%$ \\
\hline Job training school & 85 & $23 \%$ \\
\hline Bachelors & 122 & $34 \%$ \\
\hline Graduate & 71 & $20 \%$ \\
\hline Total & 360 & $100 \%$ \\
\hline \multicolumn{3}{|c|}{ Household with a member younger than 14} \\
\hline None & 253 & $70 \%$ \\
\hline One & 94 & $26 \%$ \\
\hline Two & 10 & $3 \%$ \\
\hline Three & 3 & $1 \%$ \\
\hline Total & 360 & $100 \%$ \\
\hline \multicolumn{3}{|c|}{ Household with a member older than 50} \\
\hline None & 199 & $55 \%$ \\
\hline One & 40 & $11 \%$ \\
\hline Two & 115 & $32 \%$ \\
\hline Three & 5 & $2 \%$ \\
\hline No response & 1 & 0 \\
\hline Total & 360 & $100 \%$ \\
\hline
\end{tabular}


Table 4 Pistachio purchase behavior

\begin{tabular}{|c|c|c|}
\hline$(n=360)$ & Frequency & Percent \\
\hline \multicolumn{3}{|l|}{ Purchase quantity/store visit (grams) } \\
\hline 500 or less & 167 & $46 \%$ \\
\hline $501-1000$ & 87 & $24 \%$ \\
\hline $1001-1500$ & 17 & $5 \%$ \\
\hline Above 1500 & 89 & $25 \%$ \\
\hline Total & 360 & $100 \%$ \\
\hline \multicolumn{3}{|l|}{ Purchase frequency } \\
\hline Once per month or more often & 110 & $31 \%$ \\
\hline Once every two to three month & 45 & $12 \%$ \\
\hline When celebrate major holidays only & 135 & $38 \%$ \\
\hline Do not purchase pistachio nuts & 70 & $19 \%$ \\
\hline Total & 360 & $100 \%$ \\
\hline \multicolumn{3}{|c|}{ Compare to last year, this year your family purchased more pistachios or less? } \\
\hline More & 65 & $22 \%$ (20\% increase) \\
\hline Not change & 196 & $68 \%$ \\
\hline Less & 29 & $10 \%$ (25\% decrease) \\
\hline Total & 290 & $100 \%$ \\
\hline \multicolumn{3}{|c|}{ Often purchase domestic produced or imported? } \\
\hline Domestic produced & 117 & $40 \%$ \\
\hline Imported & 40 & $14 \%$ \\
\hline Both & 79 & $27 \%$ \\
\hline Do not know country of origin & 54 & $19 \%$ \\
\hline Total & 290 & $100 \%$ \\
\hline \multicolumn{3}{|c|}{ Often purchase for family use or as a gift to others } \\
\hline For family & 233 & $80 \%$ \\
\hline Use as a gift & 10 & $3 \%$ \\
\hline Both & 45 & $15 \%$ \\
\hline I do not know & 2 & $1 \%$ \\
\hline Total & 290 & $100 \%$ \\
\hline \multicolumn{3}{|l|}{ Where do you often shop for pistachios? } \\
\hline Large supermarkets & 169 & $58 \%$ \\
\hline Midsize- small- supermarkets & 62 & $21 \%$ \\
\hline Dry nuts wholesale store & 30 & $10 \%$ \\
\hline Dry nuts retail store & 18 & $6 \%$ \\
\hline Wet markets & 7 & $2 \%$ \\
\hline Online store & 4 & $1 \%$ \\
\hline Total & 290 & $100 \%$ \\
\hline \multicolumn{3}{|c|}{ Have you heard about California pistachios } \\
\hline Yes & 226 & $74 \%$ \\
\hline No & 81 & $26 \%$ \\
\hline Total & 307 & $100 \%$ \\
\hline \multicolumn{3}{|l|}{ Have you purchased California pistachios } \\
\hline Yes & 150 & $52 \%$ \\
\hline No & 138 & $48 \%$ \\
\hline
\end{tabular}


Table 4 Pistachio purchase behavior (Continued)

\begin{tabular}{lll}
\hline Total & 288 & $100 \%$ \\
Do you like to try California pistachios & & \\
Yes & 154 & $94 \%$ \\
No & 10 & $6 \%$ \\
Total & 164 & $100 \%$ \\
\hline
\end{tabular}

respondents do make a purchase at least once per months and the average consumption amount for this group is 640 gram per visit. This group consumes pistachio on a daily basis. Our sample also suggests that compared to the last year (year 2010), 22\% of the respondents have increased the purchase by $20 \%$; $68 \%$ have purchased a similar amount; and $10 \%$ have decreased the purchase by $25 \%$. Though the interview did not ask reasons behind the consumption change, possible explanations include change in income and food preference, food safety concerns, and newly availability of imported pistachios.

COO appears to affect pistachio purchase: $40 \%$ of the respondents often purchase domestically produced pistachio only; $14 \%$ prefer imported nuts only; $27 \%$ purchase both; and $19 \%$ do not know the $\mathrm{COO}$ of the pistachios. Thus, the statistics seem to indicate that domestically produced nuts are more popular than imported nuts. Most purchase was made for own consumption only (80\%). Only a few purchases were made for gift purpose (3\%) and more purchase was made for both occasions (15\%). Thus, pistachios are primary used for own consumption. This finding is out of our expectation as we expect more purchase would be made for gift purposes, especially during the holiday seasons. The result possibly indicates that pistachio is not any more a luxury item to entertain friends or relatives during major holidays. Rather it is considered as a daily snack to be consumed by respondents' own family.

Most purchases took place at supermarkets of different size (79\%) with only $16 \%$ purchases were made at wholesale or retail dry nuts store. Purchase is less likely to be made at wet markets or online stores (3\%). Many respondents have heard about California produced pistachio (74\%); $52 \%$ of them have purchased California pistachio; and $94 \%$ would like to try California pistachios in the future.

Results of the main effect model appear in Table 5. The likelihood ratio test, the Prob > $\mathrm{Chi}^{2}$ score, and the Wald $\mathrm{chi}^{2}$ results suggest that the conditional logit model is a good fit. Specifically, the likelihood ratio test rejects the null hypothesis that none of the selected attributes contribute to the derived utility. At least one of the selected attributes has a statistically significant impact on the estimated utility. Coefficient estimates of the conditional logit model describe the effect of each selected attribute on the overall derived utility of pistachio consumption. Coefficients for the California alternative and the Chinese alternative are both positive and statistically significant (alpha < 0.0001), meaning that pistachio from these two countries are greatly preferred over the no purchasing option. Thus, the sample suggests that responding Chinese consumers appreciate Chinese pistachio as well as imported pistachio from California. However, the bigger coefficient of the California variable than the Chinese variable further suggests that California pistachio adds more to the derived utility than the Chinese alternative. A likelihood ratio test was then conducted to find out whether Chinese consumers like California pistachio better than Chinese pistachio in a statistically significant way. 
Table 5 Conditional logit model coefficients

\begin{tabular}{lll}
\hline Variables & Coefficient & $\mathbf{P}>|\mathbf{z}|$ \\
\hline China** & 0.7311 & $<0.0001$ \\
California*** & 1.077 & $<0.009$ \\
Turkey*** & -0.4739 & $<0.0001$ \\
Price*** & -0.1913 & $<0.0001$ \\
Salty Flavor & -0.0135 & 0.895 \\
Sweet Flavor*** & -0.3856 & $<0.0001$ \\
Gift Pack & 0.049 \\
250-gram Pack & -0.1677 & 0.054 \\
500-gram Pack & 0.0192 & 0.252 \\
Likelihood ratio & -0.1208 & \\
Wald chi2(6) & -1361 & \\
Prob $>$ chi2 & 35.34 & \\
\hline Standard errors are in parentheses; *** means statistically significant at 1\% level ** means 5\% level.
\end{tabular}

The LR statistics is 187.6 with 1 degree of freedom, indicating that Chinese consumers prefer California pistachio significantly better. The statistically significant negative coefficient of the Turkey variable suggests that the no-purchase option is preferred to the purchase of Turkish pistachio. Thus, California pistachio is most preferred, followed by the Chinese alternative, and the Turkish pistachio is least favored.

The negative and statistically significant price coefficient indicates rational consumption behavior: Chinese consumers prefer the lower priced items rather than the high priced alternatives. In contrast, when researching food consumption in China, several researchers have found that Chinese consumers' purchasing behavior contradicts with the demand theory: the higher priced items often result in greater quantity demanded, due to heightened food safety concerns (Herrmann et al. 2006; Wang 2003; Xu et al. 2010). For example, $\mathrm{Xu}$ et al. 2010 showed that Chinese college students prefer higher priced milk because they believe the milk is safer than lower priced options. Different from milk, which is consumed on a daily basis, to most respondents, pistachio is less frequently consumed. In addition, milk contaminations are publicized so frequently such that it has been difficult to restore consumption confident (Xu et al. 2010). In contrast, pistachio contamination was once uncovered in 2013, but later on more news have emphasized the healthful and beneficial features of pistachios. Thus, food safety appears less a concern and price is still a primary factor changing pistachio choices.

The sweet and salty flavor was compared with the original non-flavor to understand if Chinese consumers prefer original pistachio to the flavored alternatives. The original flavor is significantly preferred to the sweet flavor, as suggested by the negative coefficient of the Sweet Flavor variable. Though the salty flavor is not significantly preferred to the original flavor, both salty- and original- flavored are more attractive than the sweet flavored pistachios.

Our sample also suggests that a non-gift packed product is preferred to the giftpacked alternative. This finding further confirms the fact that pistachio is popularly used for own-consumption instead of a gift. Consumers desire the non-gift packed rather than the more expensive gift-packed alternatives. This finding again indicates how price sensitive Chinese consumers are when selecting pistachios. However, Chinese 
consumers are found to be less sensitive to package size change. The two package-size variables are not significant, indicating that consumers like the 125 -gram pack the same as they like the 250-gram or the 500-gram pack. Small packs are convenient which may especially attract younger consumers. More than ten years ago, Veeck and Veeck (2000) discovered that younger consumers with higher disposable income but little shopping time would value the convenience of food. The small pack may perfectly meet the needs of this group. The larger 500-gram pack, in contrast, may fit the needs of older consumers, who have a bigger family to support and who are more sensitive to price. Given larger packs usually come with a quantity discount, this older consumer group tends to favor the larger packs.

Following Mayen et al. (2007), the relative importance of each selected attribute over total importance were calculated (Table 6). The observed R.I. and the Bootstrap standard errors are computed using 500 random samples generated for the simple regression model (Guan, 2003). Price is the outmost important attribute that contributes to $74 \%$ of the total importance. This result again confirms the great impact of price on pistachio purchase. $\mathrm{COO}$ adds $17 \%$ to the total importance, indicating that consumers look at $\mathrm{COO}$ when making pistachio purchases. Flavor, package size, and package type are less important features. Thus, price and $\mathrm{COO}$ are two key attributes to change pistachio choice.

Marginal effects estimate how the change of attribute level affects the probability of a product being selected (Table 7). The marginal effect of price is -4.55 (alpha $<1 \%$ ), indicating that a one dollar increase in price will result in a $4.55 \%$ decrease in the probability of selecting California pistachio. The price impact is smaller for domestic Chinese pistachios (3.82\%) and for Turkey pistachios (1.45\%). Thus, compared to California and Chinese pistachios, the demand for Turkey pistachios is the least sensitive to price change. However, the demand for Turkey pistachio is also the smallest. The marginal effect for the Opt-out alternative is $3.59 \%$, indicating that if price rises, it will make it even more unlikely for the non-purchasers to buy pistachios.

Pistachio flavor and package type affect purchase probability. A move from the original to sweet flavor reduces the probability of choosing California pistachio by $9.01 \%$ and Chinese pistachio by $7.47 \%$ (alpha $<1 \%$ ). A change from gift pack to non-gift pack increases the probability of selecting California pistachios by $3.98 \%$ (alpha $<5 \%$ ), and Chinese pistachios by $3.35 \%$ (alpha $<5 \%$ ). The salty flavor and the package size attributes are not resulted in statistically significant marginal effects.

The WTP estimates are shown in Table 8. Surveyed Chinese consumers are willing to pay an additional 6.30 Yuan (equivalent $\$ 1$, exchange rate: $\$ 1=6.3$ Yuan) on average to move from Turkey to Chinese pistachios, and 8.11 Yuan (\$1.3) to move from Turkey

Table 6 Relative importance of selected attributes

\begin{tabular}{llll}
\hline & R.I. & Observed R.I. & Bootstrap standard error \\
\hline Price & 0.74 & 0.92 & 0.035 \\
COO & 0.19 & 0.17 & 0.046 \\
Flavor & 0.04 & 0.045 & 0.02 \\
Gift Pack & 0.02 & 0.02 & 0.013 \\
Pack size & 0.01 & 0.02 & 0.015 \\
\hline
\end{tabular}


Table 7 Marginal effects for conditional logit model

\begin{tabular}{lllll}
\hline Attributes & California & China & Turkey & Opt-out \\
\hline Price & $-4.55(1.25)^{* * *}$ & $-3.82(1.06)^{* * *}$ & $-1.45(0.42)^{* * *}$ & $-3.59(0.99)^{* * *}$ \\
Origin to Salty & $-0.32(2.40)$ & $-0.27(2.03)$ & $-0.10(0.77)$ & $-0.25(1.91)$ \\
Origin to Sweet & $-9.01(2.42)^{* * *}$ & $-7.47(1.99)^{* * *}$ & $-2.78(0.76)^{* * *}$ & $-6.53(1.62)^{* * *}$ \\
Gift to None-gift & $3.98(2.02)^{* *}$ & $3.35(1.71)^{* *}$ & $1.27(0.65)^{*}$ & $3.01(1.47)^{* *}$ \\
125- to 250-gram & $0.45(2.47)$ & $0.38(2.08)$ & $0.14(0.79)$ & $0.36(1.97)$ \\
125- to 500-gram & $-2.86(2.48)$ & $-2.3(2.07)$ & $-0.90(0.77)$ & $-2.19(1.86)$ \\
\hline
\end{tabular}

Standard errors are in parentheses; ${ }^{* * *}$ means statistically significant at $1 \%$ level; ${ }^{* *}$ means $5 \%$ level; ${ }^{*}$ means $10 \%$ level.

to California pistachios. The $95 \%$ confidence interval does not include a zero, indicating that the WTP estimates are significantly different from zero. Thus, respondents' WTP is the highest for California pistachios, followed by the Chinese option and the Turkish pistachios the lowest. Surveyed Chinese consumers are willing to pay a higher premium for their preferred California or Chinese pistachio than the Turkey option.

Chinese consumers are willing to pay a small premium for pistachio with original, no-salt and no-sugar flavor. The average WTP is 2.02 Chinese Yuan (\$ 0.3) to move from sweet pistachios to an original product. The WTP estimate is not statistically significant for the Original to Salty variable, meaning Chinese consumers do not prefer original flavor to salty flavor. Combining this result with results in Table 7, we conclude that original or salty flavor is more attractive than the sweet flavor. WTP estimates are not significant for the package type and package size variables, indicating that respondents' WTP will not change with package type and package size. The WTP estimates are the greatest for the $\mathrm{COO}$ attributes, followed by the original flavor attributes. In addition, respondents will not pay a premium for preferred package type or package size. This result agrees with the relative importance estimates in Table 6. The WTP estimate for package type in Table 8 is insignificant, but the coefficient estimate for package type is significant in Table 5. This seems to suggest that respondents consider package type when purchasing pistachio, however, they will not pay a premium for pistachios that have a preferred package type.

Consumer characteristics were found to interact with product attributes to change choice preference (Louviere et al., 2000). This study further addresses the interaction effects and uses a mixed logit model to estimate how $\mathrm{COO}$ effect would change with income (Table 9). The likelihood ratio test, the Prob $>\mathrm{chi}^{2}$ score, and the Wald $\mathrm{chi}^{2}$ results all suggest that the mixed logit model is a good fit. COO, price, sweet flavor and pack type that were significant in the conditional logit model remain significant in the

Table 8 WTP estimates for conditional logit model

\begin{tabular}{llllc}
\hline Change in attributes & Mean WTP & Standard deviation & \multicolumn{2}{l}{$\mathbf{9 5 \% \text { confidence interval }}$} \\
\hline Turkey to Chinese & 6.3 & 1.85 & 2.67 & 9.93 \\
Turkey to California & 8.11 & 2.3 & 3.6 & 12.61 \\
Original to salty & 0.07 & 0.53 & -0.98 & 1.12 \\
Sweet to original & 2.02 & 0.78 & 0.48 & 3.55 \\
Gift to non-gift pack & 0.88 & 0.51 & -0.12 & 1.88 \\
125- to 250-gram & 0.1 & 0.54 & -1.17 & 0.97 \\
125- to 500-gram & -0.63 & 0.58 & -0.5 & 1.76 \\
\hline
\end{tabular}


Table 9 Mixed logit model coefficients

\begin{tabular}{lll}
\hline Variables & Coefficient & $\mathbf{P}>|\mathbf{z}|$ \\
\hline China** $^{*}$ & 0.5261 & 0.049 \\
California* $^{*}$ & 0.5132 & 0.044 \\
Turkey** $^{* *}$ & 0.01 \\
Price*** & -0.4689 & $<0.0001$ \\
Salt Flavor & -0.1929 & 0.973 \\
Sweet Flavor** & -0.0034 & $<0.0001$ \\
Gift Package** & -0.3947 & 0.045 \\
250-gram Pack & -0.1716 & 0.839 \\
500-gram Pack & 0.0212 & 0.229 \\
Chinese X Income & -0.1272 & 0.332 \\
California X Income & 0.005 \\
Likelihood ratio & 0.0192 & \\
Wald chi2 (8) & 0.0513 & \\
Prob > chi2 & -1353 & \\
\hline
\end{tabular}

Standard errors are in parentheses; ${ }^{* * *}$ means statistically significant at $1 \%$ level; ${ }^{* *}$ means $5 \%$ level.

mixed logit model. The California and income interaction effect is positive and statistically significant at $1 \%$ level, suggesting that the purchase of California pistachios depends on income. Respondents with a higher income tend to purchase California pistachios. The marginal effect shows that: every $1 \%$ increase in income will result in a $1.2 \%$ increase in the probability of choosing California nuts. The Chinese and income interaction effect is positive but not statistically significant, meaning that the higher income will not generate the purchase of Chinese pistachios. The COO impact on derived utility is reduced in this income effect model compared to the main effect model ( 0.7311 to 0.5261 for China and 1.077 to 0.5132 for California). Thus, wealthier respondents tend to derive additional utility from the consumption of California pistachios.

WTP for the mixed logit model appears in Table 10. On average, surveyed consumers are willing to pay an extra of 5.16 Yuan $(\$ 0.82)$ for Chinese pistachios, and 5.09 Yuan (\$0.81) more for California pistachios compared to the Turkish alternative. WTP is the highest for Chinese pistachios, followed by the California alternative, and the Turkish pistachios resulted in the lowest WTP. WTP estimates for the Sweet to Original variable is significantly different from zero, meaning that consumers value original flavored

Table 10 WTP estimates for mixed logit model

\begin{tabular}{lllll}
\hline Change in attributes & Mean WTP & Standard deviation & \multicolumn{2}{c}{$\mathbf{9 5 \% \text { confidence interval }}$} \\
\hline Turkey to Chinese & 5.16 & 1.9 & 1.44 & 8.88 \\
Turkey to California & 5.09 & 1.84 & 1.49 & 8.69 \\
Original to Salty & 0.02 & 0.53 & -1.02 & 1.06 \\
Sweet to Original & 2.05 & 0.79 & 0.51 & 3.59 \\
Gift pack to None-gift & 0.89 & 0.51 & -0.11 & 1.89 \\
125- to 250- gram pack & 0.11 & 0.54 & -1.17 & 0.95 \\
125- to 500- gram pack & -0.66 & 0.58 & -0.47 & 1.79 \\
Chinese * Income & 0.1 & 0.1 & -0.1 & 0.3 \\
California * Income & 0.27 & 0.09 & 0.08 & 0.45 \\
\hline
\end{tabular}


pistachios. The income interaction indicates that wealthier respondents are willing to pay an additional 27 cents for California pistachios. WTP estimates for the flavor variable, the package type and package size variables are not significant, meaning that respondents' purchase choice is less likely to be affected by these attributes.

\section{Conclusions}

China's already expanded pistachio demand will continue to grow due to its strong economic development and the presence of wealthy consumer segments. The greater disposable income enables these new consumption segments to purchase imported California pistachios. These emerging affluent consumers are found to be willing to pay a price premium for California pistachios. Moreover, their demand is found to be rational, meaning that they are willing to pay a higher price for California nuts than Chinese nuts, but they are only interested in reasonably priced California nuts. Thus, California pistachios are attractive only if their price is comparable to that of domestic Chinese nuts. In terms of preferred flavor, the affluent segments want the no-salt and no-sugar flavor or the salty flavor more than the sweetened nuts. To them, non-gift pack seems to be more attractive than the gift pack, indicating that pistachios are popularly consumed in the family rather than exclusively used as a gift.

China's pistachio consumers are increasingly diversified to include the less wealthy consumers. Similarly to the rich group, this less affluent segment cares product price, values product origin, and wants the original flavored pistachios. Perhaps due to limited income this segment prefers domestic Chinese pistachios. The diversified consumption group may predict a demand bust and a great market opportunity to domestic as well as international pistachio shareholders. Our results suggest that California pistachio suppliers should take advantage of the high price willingness to pay from the wealthier consumers. Domestic Chinese suppliers may focus on the less affluent groups to address their needs of lower priced pistachios.

$\mathrm{COO}$ as a salient quality cue is found to affected Chinese consumers' pistachio needs. Chinese consumers favor California pistachios the most and Turkish pistachios the least. Domestic Chinese pistachios are more desirable than Turkish nuts, perhaps due to better product knowledge, positive consumption experiences, and easier market accesses. In the Western behavioral literature, better product knowledge explains enhanced preference rating (Bilkey and Nes, 1982). In the Chinese setting, American Pistachio Growers Association showcased the healthfulness of California pistachios in China's two largest pistachio consumption cities of Beijing and Shanghai in 2011 (Cq people.cn, 2011). This and other market promotion programs may have acquainted Chinese consumers with California pistachios and helped California pistachios establish a greater market share.

Competing interests

Both authors declare that they have no competing interests.

Authors' contributions

PX and ZW designed the Questionaire; ZW gathered data; PX analyzed data and drafted the manuscript. PX and ZW revised the manuscript. Both authors read and approved the final manuscript. 
Received: 30 December 2013 Accepted: 14 August 2014

Published online: 24 September 2014

\section{References}

Askci.com (2012) China Imported Olive Oil from Turkey Would Arrive 464 Tons in 2012., http://www.askci.com/news/ 201206/06/9301_55.shtml Assessed 4 June 2014

Beijing Statistical Information Net (2011)., http://www.bjstats.gov.cn/sjfb/bssj/jdsj/2011/201109/t20110914_210867.htm Assessed 4 June 2014

Bilkey W, Nes E (1982) Country of Origin Effects on Product Evaluations. J Int Bus Stud 8(Spring/Summer):89-99

Blackman J, Saliba A, Schmidtke L (2010) Sweetness Acceptance of Novices, Experience Consumers and Winemakers in Hunter Valley Semillon Wines. Food Qual Prefer 21:679-683

Chang KL, Xu P, Underwood K, Mayen C, Langelett G (2012) Consumers' Willingness to Pay for Locally Produced Ground Beef: A Case Study of the Rural Northern Great Plains. J Int Food Agribus Mark 25(1):42-67

Chen G, Cao GY, Liu YB, Pang LH, Zhang L, Ren Q, Wang HT, Zheng XY (2006) The Future Population of Beijing - A Projection on the Population, Human Capital and Urbanization Using PDE Model. J Mark Popul Anal 12(4):29-41

China Food News (2012) Sales Management and Brand Management to Expand the Pistachio Market., August 2, 2012. http://www.cnfood.cn/npage/shownews.php?id=8838 Assessed 4 June 2014

China Commerce (2013) Food Safety: The China Dream., http://finance.sina.com.cn/leadership/mroll/20130407/ 103515062173.shtml Accessed 5 June 2014

Colombo SJ, Calatrave-requena J, Hanley N (2007) Testing Choice Experiment for Benefit Transfer with Preference Heterogeneity. Am J Agr Econ 89:135-151

Cq People.cn (2011) Pistachio Grower Association and Lady California Promoted U.S. Pistachio to Beijing Consumers, http://cq.people.com.cn/newscenter/cq/news.cqr300?Num=7467833. Assessed 4 June 2014

Daillant-spinnler B, MacFie HJH, Beyts PK, Hedderley D (1996) Relationships between Perceived Sensory Properties and Major Preference Directions of 12 Varieties of Apply from Southern Hemisphere. Food Qual Prefer 7:112-126

De Steur H, Gellynck X, Feng SY, Rutsaert P, Verbeke W (2012) Determinants of Willingness-to-pay for GM Rice with health Benefits in a High-risk region: Evidence from Experimental Auctions for Folate Biofortified Rice in China. Food Qual Prefer 25:87-94

Erickson GM, Johansson JK, Chao P (1984) Image Variables in Multi-attribute Product Evaluations: Country-of-Origin Effects. J Consum Res 11(2):694-699

Enorth (2008) California Pistachio Seeks to Increase its Market Share in China., http://economy.enorth.com.cn/system/ 2008/05/29/003328840.shtml. Assessed 4 June 2014

Fuller F, Huang J, Ma H, Rozelle S (2006) Got Milk: The Rapid Rise of China's Dairy Sector and Its Future Prospects. Food Policy 31:201-215

Greene WH (2000) Econometric Analysis, 5th edn. Prentice Hall

Guan WH (2003) From the Help Desk: Bootstrapped Standard Errors. The Stata Journal 3(1):71-80

Herrmann M, Xu P, Dong LC, Fong QS, Crapo C (2006) Rating Alaska Salmon Protein Concentrate in China. J Food Prod Mark 12(1):57-85

Hu W, Woods T, Bastin S (2009) Consumer Acceptance and Willingness to Pay for Blueberry Products with Nonconventional Attributes. J Agr Appl Econ 41(1):47-60

Laing DG, Prescott J, Bell GA, Gillmore R, Allen S, Best DJ, Yoshida M, Yamazaki K, Ishii-Mathews R (1994) Responses of Japanese and Australians to sweetness in the context of different foods. J Sens Stud 9(2):131-155

Lancaster K (1966) A New Approach to Consumer Theory. J Polit Econ 74:132-157

Louviere J, Hensher D, Swait J (2000) Stated Choice Methods: Analysis and Applications, 1st edn. Cambridge University Press, Cambridge, U.K.

Lusk JL, Norwood FB (2005) Effect of Experimental Design on Choice-Based Conjoint Valuation Estimates. Am J Agr Econ 87(3):771-785

Loureiro ML, Umberger WJ (2007) A Choice Experiment Model for Beef: What U.S. Consumer Responses Tell Us About Relative Preferences for Food Safety, Country-of-Origin Labeling and Traceability. Food Policy 32:496-514

Mayen C, Marshall MI, Lusk JL (2007) Fresh-cut Melon-The Money Is in the Juice. J Agr Appl Econ 39(3):597-609

McFadden D (1974) Conditional Logit Analysis of Qualitative Choice Behavior. In: Zarembka P (ed) Frontiers of Econometrics. Academic Press, New York

Ortega DL, Wang HH, Olynk N, Bai J, Wu L (2011) Chinese Consumers Demand for Food Safety Attributes: A Push for Government and Industrial Regulations. Am J Agr Econ 94(2):489-495

PistachioHealth.com, (2012) World Pistachio Day: A Global Chance to Celebrate the Wonderful Green Nuts., http://wwwprnewswirecom/news-releases/world-pistachio-day-a-global-chance-to-celebrate-the-wonderful-greennut-85334192html Assessed 4 June 2014

Prescott J, Bell GA, Gillmore R, Yoshida M, Laining DG, Allen S, Yamazaki K (1993) Responses of Japanese and Australians to Saltiness in the context of foods. Chem Senses 18(5):616

Schnettler B, Manquilef O, Miranda H (2004) Attributos valorados en la seleccion de carne bovina en supermercados de Temuco, IX Region de Chile. Sci Agri Res 31(2):91-100

Schnettler B, Ruiz D, Sepulveda O, Sepulveda N (2008) Importance of the Country of Origin in Food Consumption in a Developing Country. Food Qual Prefer 19:372-382

Sohu (2009) China's Food Safety Inspection Bureau: China Rejected U.S. Produced Pistachio., http://baobao.sohu.com/ 20090411/n263326197.shtml Assessed 4 June 2014

South China Morning Post (2013) Chinese Consumers Go Crazy for California Pistachios., http://www.scmp.com/news/ hong-kong/article/1295877/chinese-consumers-go-crazy-californian-pistachios Assessed 4 June 2014

Tech-Food.com (2006) China Leads the World's Pistachio Consumption., in Chinese http://wwwtech-foodcom/news/ 2006-11-21/n0083060htm Accessed 2 March 2013 
The Six National Population Census, Beijing (2014)., http://www.bjstats.gov.cn/rkpc_6/pcsj/201105/t20110530_203327. htm Accessed 2 June 2014

Train K (2003) Discrete Choice Methods with Simulation. Cambridge University Press, Cambridge, U.K.

USDA (2003) World Pistachio Situation and Outlook., http://www.agrostrat.gr/?q=en/node/279. Assessed 4 June 2014 Veeck A, Veeck G (2000) Consumer Segmentation and Changing Food Purchase Patterns in Nanjing, PRC. World Dev 28(3):457-471

Wang ZG (2003) Consumers' recognition of food safety and their decision making for consumption. Chinese Rural Eco 4:41-51

Wang Z, Mao Y, Gale F (2008) Chinese Consumer Demand for Food Safety Attributes in Milk Products. Food Policy 33:27-36

Weston S (2013) China Consumes 17\% of California's Pistachio Crop., http://www.foodbev.com/news/china-consumes17-of-californias-pistach\#.UnvkKZRVR8s. Assessed 4 June 2014

White P, Cundiff ED (1978) Assessing the Quality of Industrial Products. J Mark 42(January):80-86

Xu P, Zheng S, Motamed M (2010) Perceived Risks and Safety Concerns about Fluid Milk among Chinese College Students. Agri Econ - Czech 56(2):67-78

Xu P, Fong QC, Zeng YC, Lone T, Liu YY (2012) Chinese Consumers' Willingness-to-Pay for Green- and Eco- Labeled Seafood. Food Control 28:74-82

Zhang CP, Bai JF, Lohmar BT, Huang JK (2010) How Do Consumers Determine the Safety of Milk in Beijing, China? China Econ Rev 21:545-554

Zheng S, Xu P, Wang Z, Song S (2012) Willingness to Pay for Traceable Pork in Beijing, China. China Agri Econ Rev 4(2):200-215

doi:10.1186/s40100-014-0014-1

Cite this article as: $\mathrm{Xu}$ and Wang: Country of origin and willingness to pay for pistachios: a chinese case. Agricultural and Food Economics 2014 2:14

\section{Submit your manuscript to a SpringerOpen ${ }^{\circ}$ journal and benefit from:}

- Convenient online submission

- Rigorous peer review

- Immediate publication on acceptance

- Open access: articles freely available online

- High visibility within the field

Retaining the copyright to your article

Submit your next manuscript at $\boldsymbol{~ s p r i n g e r o p e n . c o m ~}$ 